\title{
Síndrome de Sjögren diagnosticada após infecção por SARS-CoV-2 em paciente com diabetes autoimune latente do adulto (LADA)
}

Sjögren's syndrome diagnosed after SARS-CoV-2 infection in a patient with latent autoimmune diabetes of the adult (LAD)

Sjögren's syndrome diagnosed after infection by SARS-CoV-2 in a patient with latent autoimmune diabetes in adults (LADA)

\author{
Bárbara Queiroz de Figueiredo \\ ORCID: https://orcid.org/0000-0003-1630-4597 \\ Centro Universitário de Patos de Minas, Brasil \\ barbarafigueiredo@unipam.edu.br \\ Rúbia Carla Oliveira \\ ORCID: https://orcid.org/0000-0002-7162-3497 \\ Centro Universitário de Patos de Minas, Brasil \\ rubiacoliveira@unipam.edu.br
}

\begin{abstract}
Resumo
Introdução: As doenças autoimunes referem-se a um espectro de condições nas quais o sistema imunológico ataca erroneamente o próprio corpo, resposta autoimune que, frequentemente, envolve imunidade adaptativa desregulada (mediada por linfócitos B e T) para autoantígenos anatômicos, como a insulina. Objetivo: evidenciar um relato de caso de Síndrome de Sjögren diagnosticada após infecção por SARS-CoV-2 em paciente com diabetes autoimune latente do adulto (LADA), a fim de hipotetizar a relação entre o vírus e o desenvolvimento da doença. Metodologia: artigo trata-se de um estudo de caso clínico com perspectiva qualitativa e descritiva, que consiste em uma pesquisa em que, em geral, ocorre com coleta direta de dados, cujo o pesquisador é o instrumento indispensável. Relato de caso: Após infecção por SARS-CoV-2 em fevereiro de 2020, a paciente, após apresentar lacrimejamento nos olhos, dores articulares, xeroftalmia, xerostomia e erupções cutâneas, foi coletado os dados detalhados do exame físico, e exames complementares foram solicitados - hematológicos (hemograma, amilase, cálcio sérico, fosfatase alcalina) e de imagem (ultrassonografia das glândulas parótidas) - para elaboração do diagnóstico, os quais revelaram alterações nos níveis séricos da amilase (300 U/l), distribuído pelo parênquima da parótida bilateralmente, com aspecto sugestivo de processo inflamatório e diagnosticada com Síndrome de Sjögren. Considerações finais: Acredita-se que o Covid-19 possua características clínicas semelhantes às doenças autoimunes, pois ambas compartilham grandes reações imunes da patogênese, e que o Sars-CoV-2 pode alterar a autotolerância e gerar respostas autoimunes através da reatividade cruzada com células hospedeiras, conforme exposto pelo caso, em relação à Síndrome de Sjögren.
\end{abstract}

Palavras-chave: Síndrome de Sjögren; Covid-19; Autoimunidade; Citocinas.

\begin{abstract}
Introduction: Autoimmune diseases refer to a spectrum of conditions in which the immune system mistakenly attacks the body itself, an autoimmune response that often involves unregulated adaptive immunity (mediated by B and T lymphocytes) to anatomical autoantigens such as insulin. Objective: To demonstrate a case report of Sjögren's Syndrome diagnosed after SARS-CoV-2 infection in a patient with latent adult autoimmune diabetes (LAD), in order to hypothesize the relationship between the virus and the development of the disease. Methodology: this article is a clinical case study with a qualitative and descriptive perspective, which consists of a research in which, in general, it takes place with direct data collection, in which the researcher is the indispensable instrument. Case report: After infection with SARS-CoV-2 in February 2020, the patient, after presenting tearing eyes, joint pain, xerophthalmia, xerostomia and skin rash, detailed physical examination data was collected, and additional tests were requested - hematological (blood count, amylase, serum calcium, alkaline phosphatase) and imaging (ultrasound of the parotid glands) - for making the diagnosis, which revealed changes in serum amylase levels (300 U/l), distributed by the parotid parenchyma bilaterally, with an aspect suggestive of an inflammatory process and diagnosed with Sjögren's Syndrome. Final considerations: It is believed that Covid-19 has clinical characteristics similar to autoimmune diseases, as both share major immune reactions of the pathogenesis, and that Sars-CoV-2 can alter self-tolerance and generate autoimmune responses through cross-reactivity with cells host, as explained by the case, in relation to Sjögren's Syndrome.
\end{abstract}

Keywords: Sjögren's Syndrome; Covid-19; Autoimmunity; Cytokines. 


\begin{abstract}
Resumen
Introducción: Las enfermedades autoinmunes se refieren a un espectro de condiciones en las que el sistema inmunológico ataca por error al propio cuerpo, una respuesta autoinmune que a menudo involucra una inmunidad adaptativa no regulada (mediada por linfocitos $\mathrm{B}$ y $\mathrm{T}$ ) a autoantígenos anatómicos como la insulina. Objetivo: Demostrar el reporte de un caso de Síndrome de Sjögren diagnosticado luego de una infección por SARS-CoV-2 en un paciente con diabetes autoinmune latente del adulto (DAI), con el fin de hipotetizar la relación entre el virus y el desarrollo de la enfermedad. Metodología: este artículo es un estudio de caso clínico con perspectiva cualitativa y descriptiva, que consiste en una investigación en la que, en general, se desarrolla con recolección directa de datos, en la que el investigador es el instrumento indispensable. Caso clínico: Tras la infección por SARS-CoV-2 en febrero de 2020, la paciente, tras presentar lagrimeo en los ojos, dolor articular, xeroftalmía, xerostomía y erupción cutánea, se recogieron datos detallados de la exploración física y se solicitaron pruebas complementarias hematológicas (hemograma , amilasa, calcio sérico, fosfatasa alcalina) e imagenología (ecografía de las glándulas parótidas) - para realizar el diagnóstico, que reveló cambios en los niveles séricos de amilasa (300 U / 1), distribuidos por el parénquima parotídeo de forma bilateral, con un aspecto sugestivo de un proceso inflamatorio y diagnosticado con síndrome de Sjögren. Consideraciones finales: Se cree que Covid-19 tiene características clínicas similares a las enfermedades autoinmunes, ya que ambas comparten reacciones inmunes importantes de la patogénesis, y que Sars-CoV-2 puede alterar la auto-tolerancia y generar respuestas autoinmunes a través de reactividad cruzada con células. anfitrión, según explica el caso, en relación con el Síndrome de Sjögren.
\end{abstract}

Palabras clave: Síndrome de Sjögren; Covid-19; Autoinmunidad; Citoquinas.

\title{
1. Introdução
}

As doenças autoimunes referem-se a um espectro de condições nas quais o sistema imunológico ataca erroneamente o próprio corpo, resposta autoimune que, frequentemente, envolve imunidade adaptativa desregulada (mediada por linfócitos B e T) para autoantígenos anatômicos, como a insulina (Wang et al. 2015). Esforços para entender a autoimunidade têm sido perseguidos incessantemente por várias décadas. Tornou-se aparente que o sistema imunológico desenvolveu múltiplos mecanismos para controlar a autorreatividade, e defeitos em um ou mais desses mecanismos podem levar a uma quebra da tolerância. Entre as inúmeras lesões associadas à doença, as mais comuns parecem afetar a tolerância periférica ao invés da tolerância central. O gatilho inicial para distúrbios autoimunes sistêmicos e distúrbios autoimunes específicos de órgãos provavelmente envolve o reconhecimento de moléculas próprias ou estranhas, especialmente ácidos nucléicos, por sensores inatos. Tal reconhecimento, por sua vez, desencadeia respostas inflamatórias e o engajamento de células T e B autorreativas previamente quiescentes (Theofilopoulos et al. 2017).

O diabetes autoimune latente em adultos (LADA) é um subtipo de diabetes autoimune de tipo 1. Por ser latente e de lenta progressividade, os critérios de diagnóstico de LADA ainda são muito confusos, levando a uma alta taxa de diagnósticos incorretos. Trata-se de uma forma de diabetes em que a autoimunidade contra as células beta pancreáticas se desenvolve de maneira mais arrastada e a obrigatoriedade do uso da insulina pode se dar após vários de diagnóstico. No LADA, a disfunção da célula $\beta$ tem sido reportada como intermediária entre os dois principais tipos de diabetes mellitus. A epidemiologia do diabetes autoimune, incluindo o diabetes tipo 1, é influenciada pela suscetibilidade genética, que modifica a idade no início. Há evidências em diabetes autoimune para um continuum de suscetibilidade genética, que se estende de um efeito marcante no diabetes tipo 1 de início na infância até o efeito relativamente limitado detectado em LADA (Figueiredo et al. 2021).

Embora as etiologias de várias doenças autoimunes permaneçam completamente conhecidas, vários fatores têm sido associados a respostas autoimunes, incluindo genética, idade, ambiente, bem como infecções virais (Arleevskaya et al. 2017). Os vírus têm sido considerados os principais fatores ambientais que desencadeiam os fenômenos autoimunes em indivíduos geneticamente suscetíveis (Lerner et al. 2017). Múltiplos mecanismos foram propostos para explicar a quebra da autotolerância por infecções virais, conforme demonstrado na figura 1. 
Figura 1: Mecanismos de autoimunidade induzida por vírus. (A) Modelo de mimetismo molecular: (1) Os vírus carregam epítopos estruturalmente semelhantes aos autoepítopos. (2) A apresentação de epítopos virais por células apresentadoras de antígenos (APCs) ativam células T autorreativas que se ligam a antígenos próprios e não próprios e induzem danos aos tecidos. (B) Modelo de ativação por espectador: (1) Respostas imunes antivirais não específicas e superreativas levam à liberação de autoantígenos e liberação de citocinas inflamatórias do tecido danificado. (2) O autoantígeno é captado e apresentado por APCs. (3) Células T autorreativas ativadas por APCs, levando à destruição do tecido. (C)Modelo de disseminação de epítopo: (1) Infecção viral persistente. (2) Dano contínuo ao tecido e liberação de novos antígenos próprios. (3) Os autoantígenos são captados e apresentados por APCs. (4) Ativação inespecífica de mais células T autorreativas levando à autoimunidade.

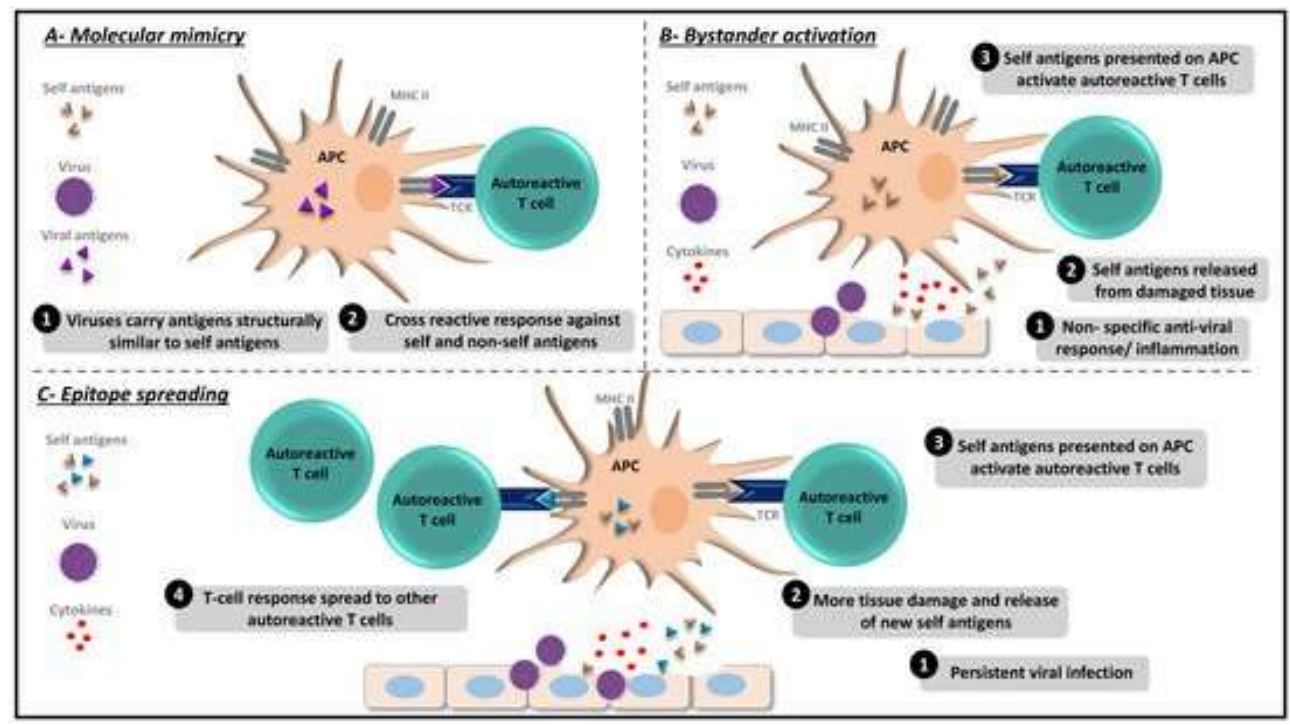

Fonte: Smatti et al. (2019).

Por muito tempo, os vírus mostraram modificar o quadro clínico de várias doenças autoimunes, incluindo diabetes tipo 1, lúpus eritematoso sistêmico, artrite reumatóide, síndrome de Sjögren, ceratite estromal herpética, doença celíaca e esclerose múltipla. Os melhores exemplos de infecções virais que foram propostas para modular a indução e o desenvolvimento de doenças autoimunes são as infecções com vírus entéricos, como vírus Coxsackie B e rotavírus, bem como vírus influenza A e herpesvírus. Outros vírus que foram estudados neste contexto incluem sarampo, caxumba e rubéola. Estudos epidemiológicos em humanos e estudos experimentais em animais mostraram que infecções virais podem induzir ou proteger de autoimunopatologias, dependendo de vários fatores, incluindo histórico genético, respostas imunes induzidas pelo hospedeiro, tipo de cepa de vírus, carga viral e o tempo de início da infecção. Ainda assim, os dados delineando a interação mecanicista clara entre o vírus e o sistema imunológico para induzir a autorreatividade são escassos (Smatti et al. 2019).

Tradicionalmente, acreditava-se que os vírus carregam antígenos estruturalmente semelhantes aos antígenos próprios, que ativam as células B e T e levam a uma resposta cruzada contra antígenos próprios e não próprios, um mecanismo conhecido como "mimetismo molecular" (Kim et al. 2006). O mimetismo molecular foi descrito para ceratite estromal induzida pelo vírus herpes simples (HSV), diabetes induzida por vírus (Coppieters et al. 2012), miocardite autoimune que é mediada pela infecção pelo vírus Coxsackie (Gaunttet al. 1995), doença desmielinizante induzida pelo vírus da encefalomielite murina de Theiler (Croxford et al. 2002). Outro mecanismo hipotético é a "ativação do espectador", em que uma resposta imune antiviral não específica e superreativa cria um ambiente pró-inflamatório localizado junto com a liberação de autoantígenos do tecido danificado (Getts et al. 2013).

Ou seja, esses autoantígenos são subsequentemente captados e apresentados por células apresentadoras de antígenos (APC) para estimular as células $\mathrm{T}$ previamente não responsivas, porém autorreativas, nas proximidades, desencadeando a 
autoimunidade (Funjinami et al. 2006). Um mecanismo relacionado é chamado de "propagação de epítopos", em que uma infecção viral desencadeia a liberação de mais autoantígenos e a ativação de novo de células autorreativas, que consequientemente se espalham para alvejar autoepítopos adicionais (Getts et al. 2013). Embora várias hipóteses tenham sido propostas para compreender os mecanismos subjacentes à autoimunidade induzida por vírus, a contribuição precisa desses mecanismos ainda não é totalmente compreendida (Smatti et al. 2019). Sob essa perspectiva, o objetivo deste estudo é evidenciar um relato de caso de Síndrome de Sjögren diagnosticada após infecção por SARS-CoV-2 em paciente com diabetes autoimune latente do adulto (LADA), a fim de hipotetizar a relação entre o vírus e o desenvolvimento da doença.

\section{Metodologia}

Este artigo trata-se de um estudo de caso clínico com perspectiva qualitativa e descritiva, que consiste em uma pesquisa em que, em geral, ocorre com coleta direta de dados, cujo o pesquisador é o instrumento indispensável. O presente estudo contou com o aporte de trabalhos acadêmicos entre os anos de 1995 e 2021. Por meio do acesso às principais bases de dados, a saber: dados National Library of Medicine (PubMed MEDLINE), Scientific Electronic Library Online (Scielo), Cochrane Database of Systematic Reviews (CDSR), Google Scholar, Biblioteca Virtual em Saúde (BVS) e EBSCO Information Services, no período compreendido entre agosto e setembro de 2021. O Termo de Consentimento Livre e Assistido (TCLE) foi assinado pelo paciente para coleta de dados neste estudo. Trata-se de um estudo de um relato de caso clínico, de abordagem qualitativa, com delineamento descritivo, de caráter narrativo e reflexivo, como intuito de proporcionar a disseminação de conhecimento na área em que se insere à comunidade científica e clínica. Os dados foram coletados em prontuário médico da USF Itamarati, associado aos exames de imagem realizados pela paciente.

\section{Relato de Caso}

Trata-se de paciente do sexo feminino, 65 anos de idade e diagnóstico de diabetes autoimune latente (LADA) em abril de 2019, que se justificou por episódios de hiperglicemias e correlação empírica com doença autoimune já existente na família, posteriormente à dosagem de anticorpos GADA contra as células beta pancreáticas, com marcação de 2000,0 UI/mL (VR: inferior a 10,0 UI/mL), bem como dosagem de hemoglobina glicada, que constou 9,3\%. Dada a identificação, a patologia seguiu-se com controle por meio de modificações dietéticas, administração insulínica de ação intermediária e lenta, a Lantus, e de ação rápida, a Asparte Fiasp, cuja dosagens variam de acordo com refeições, bem como uso diário de empagliflozina/linagliptina, ou seja, o medicamento Glyxambi, a fim de melhor controle glicêmico e melhora da qualidade de vida.

No mês de fevereiro de 2020, a paciente, após sintomatologia característica de infecção por SARS-CoV-2, realizou-se teste de RT-PCR em orofaringe para SARS-CoV-2, que resultou positivo, que evoluiu bem após prognóstico. Três meses após a sorologia positiva para Covid-19, a paciente, após apresentar lacrimejamento nos olhos, dores articulares, xeroftalmia, xerostomia e erupções cutâneas, foi coletado os dados detalhados do exame físico, e exames complementares foram solicitados - hematológicos (hemograma, amilase, cálcio sérico, fosfatase alcalina) e de imagem (ultrassonografia das glândulas parótidas) - para elaboração do diagnóstico, os quais revelaram alterações nos níveis séricos da amilase (300 U/l) e ultrassonografia com imagens hipoecoicas de aspecto nodular, distribuído pelo parênquima da parótida bilateralmente, com aspecto sugestivo de processo inflamatório.

Após detecção e diagnóstico da Síndrome de Sjögren, o tratamento proposto para paciente foi baseado em sua sintomatologia, sem repercussões sistêmicas até o momento. Lágrimas artificiais (FreshTears®) e pilocarpina foram prescritas à paciente para minimizar suas queixas, e foram dadas orientações para avaliação com reumatologista na tentativa de 
investigação de acometimento sistêmico pela doença autoimune. Também foi solicitado à paciente terapêutica com o imunomodulador hidroxicloroquina $250 \mathrm{mg}$.

\section{Discussão}

Muitos pacientes pós Covid-19 experienciam a chamada “tempestade de citocinas”, que são várias proteínas diferentes, enviadas pelas células imunológicas e por outras células, que atuam como mensageiras do sistema imunológico, que ajudam a regular uma resposta contra um inimigo indesejado. O problema é que nesse ataque, as citocinas acabam atingindo células do próprio corpo, além do inimigo, e isso pode deixar sequelas. A reação é parecida com o que se vê em pessoas com doenças autoimunes, que levam uma vida repleta de dores e danos a órgãos vitais devido à autorreatividade. Esses autoanticorpos são claramente recém-adquiridos, e apareceram durante a infecção, que pode provocar a autoimunidade (Figueiredo et al. 2021).

Foi sugerido que os mecanismos patogenéticos compartilhados e aspectos clínico-radiológicos entre as doenças hiperinflamatórias e Covid-19 podem sugerir que a SARS-CoV-2 poderia atuar como um fator desencadeante para o desenvolvimento de uma desregulação autoimune ou autoinflamatória rápida, levando, por exemplo, à pneumonia intersticial grave, em indivíduos com predisposição genética (Caso et al. 2020). Além disso, em estudo de Gagiannis et al. (2020), os autores estudaram prospectivamente um grupo de 22 pacientes quanto ao possível papel da autoimunidade na insuficiência respiratória associada à SARS-CoV-2. Com base nas semelhanças sorológicas, radiológicas e histomorfológicas entre a síndrome respiratória aguda associada a Covid-19 e a exacerbação aguda de doença pulmonar intersticial induzida por doença do tecido conjuntivo, os autores sugerem que a infecção por SARS-CoV-2 pode desencadear ou simular uma forma de autoimunidade específica de órgão em pacientes predispostos. Com base na possibilidade de detectar reações autoimunes por métodos morfológicos, Zinserling et al. (2020) analisaram autópsias de 18 pacientes falecidos por COVID-19. A investigação patológica foi feita usando linhagem brilhante de imuno-histoquímica, que permitiu demonstrar o papel de diferentes mecanismos de morte celular, conforme demonstrado na Figura 2.

Figura 2: Infiltração por células T supressoras CD8 + de diferentes órgãos.
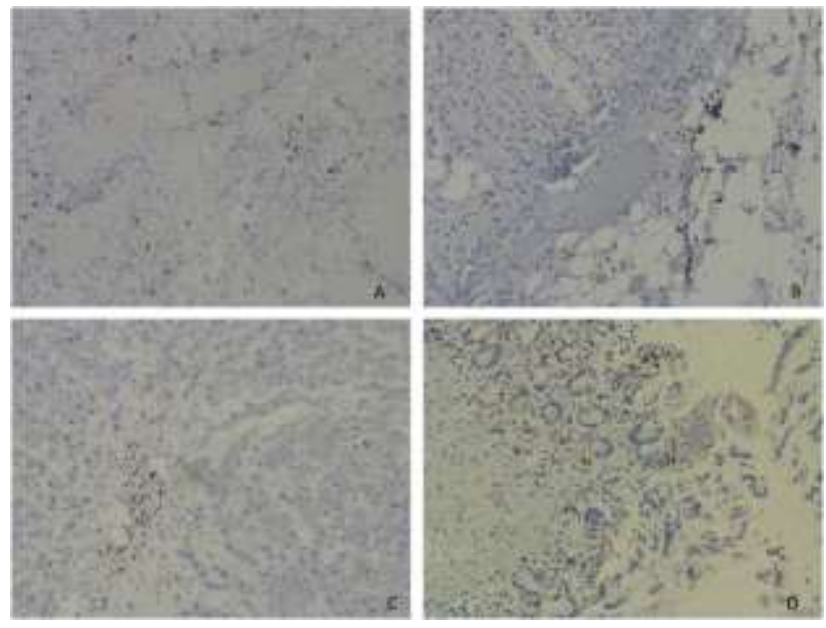

Fonte: Zinserling et al. (2020).

Com isso, nota-se a infiltração difusa dos pulmões, juntamente com a infiltração focal do rim, fígado, intestino, adrenais, pâncreas e pericárdio por linfócitos, que foram vistos em graus diferentes em todos os nossos casos. Para compreender a sua natureza, comprovou-se que o infiltrado era dominado por linfócitos T (CD3 +), sendo os mais numerosos 
deles supressores de CD8 +, observados nos pulmões (figura a), suprarrenais (figura b), fígado (figura c), intestino (figura d) e outros órgãos parcialmente acompanhados por lesões de tecido. Levando em consideração que um dos mecanismos mais importantes de reações autoimunes é a citotoxicidade mediada por células T CD8 +, presumiu-se que os achados confirmaram um processo autoimune.

A síndrome de Sjögren, diagnóstico da paciente deste estudo, é geralmente caracterizada por um curso estável e leve de manifestações glandulares e extraglandulares. No entanto, o risco de linfoma é 40 vezes maior do que na população em geral. A qualidade de vida em relação à saúde é menor em mulheres com síndrome de Sjögren primária que em mulheres saudáveis e comparáveis às mulheres com artrite reumatoide, lúpus ou fibromialgia $\mathrm{A}$ etiologia e muitos aspectos da patogênese da síndrome de síndrome de Sjögren são ainda evasivos. Vários fatores, como a predisposição genética e causas ambientais, influenciam o desenvolvimento da síndrome, e, somente após ocorrer lesão irreversível do órgão, tornam-se evidentes os sintomas clínicos. Além disso, o diagnóstico é dificultado pela heterogeneidade das manifestações que conduzem à demora do diagnóstico correto. Até o momento, não existe cura para essa doença, e o tratamento é limitado para o alívio dos sintomas (Santos et al. 2013).

\section{Considerações Finais}

Acredita-se que o Covid-19 possua características clínicas semelhantes às doenças autoimunes, pois ambas compartilham grandes reações imunes da patogênese, e que o Sars-CoV-2 pode alterar a autotolerância e gerar respostas autoimunes através da reatividade cruzada com células hospedeiras (Figueiredo et al. 2021), conforme exposto pelo caso, em relação à Síndrome de Sjögren. No entanto, ficará a cargo da comunidade científica investigar essa possibilidade mais a fundo para validar ou reprovar essa hipótese, haja vista a facilidade em detectar autoanticorpos, corroborando, dessa forma, a constatação de que eles, desencadeados ou não pela Covid-19, são realmente uma ameaça de alteração no sistema imunológico ou se trata apenas de anomalias de pesquisas.

\section{Referências}

Arleevskaya, M. I., Manukyan, G., Inoue, R. \& Aminov, R. (2017). Editorial: Fatores microbianos e ambientais em doenças autoimunes e inflamatórias. Frente. Immunol., 8 (1), 240-243.

Caso, F., Costa, L. \& Ruscitti, P. (2020). O Sars-coronavirus-2 poderia desencadear mecanismos autoimunes e / ou autoinflamatórios em indivíduos geneticamente predispostos? Autoimmun Rev., 3 (8).

Coppieters, K. T., Wiberg, A. \& Von Herrath, M. G. (2012). Infecções virais e mimetismo molecular no diabetes tipo 1. APMIS, 120 (10), $941-949$.

Croxford, J., Olson, J. K. \& Miller, S. D. (2002). Espalhamento de epítopo e mimetismo molecular como gatilhos de autoimunidade no modelo de doença desmielinizante induzida por vírus de Theiler de esclerose múltipla. Autoimmun. Rev., 1 (8), 251-260.

Figueiredo, B. Q., Araújo, A. P. F., Silva, C. D., Cabral, D. A. C., Amorim, G. S., Medeiros, G. A., Presot, I. Q., Miranda, L. D., Lessa, M. P. P. \& Delboni, V. S. (2021). Tempestade de citocinas e desenvolvimento de doenças autoimunes como sequela da Covid-19. Research, Society and Development, 10 (11), 1-8. http://dx.doi.org/10.33448/rsd-v10i11.19385

Figueiredo, B. Q., Durante, G., Amorim, G. S., Presot, I. Q., Souza, J. R., Soares, L. S., Oliveira, N. S. S., Assunção, P. E. P., Porto, S. S. \& Medeiros, V. L. O. (2021). Diabetes autoimune latente do adulto (LADA): fisiopatologia, critérios diagnósticos e associação com doenças autoimunes. Research, Society and Development, 10 (11), 1-8. http://dx.doi.org/10.33448/rsd-v10i11.19532

Fujinami, R. S., Von Herrath, M. G., Christen, U. \& Whitton, J. L. (2006). Molecular Mimicry, Bystander Activation, or Viral Persistence: Infections and Autoimmune Disease. Clin. Microbiol. Rev., 19 (12), 80-94.

Gagiannis, D., Steinestel, J. \& Hackenbroch, C. (2020). Insuficiência respiratória aguda induzida por COVID-19 - uma exacerbação de autoimunidade específica do órgão? Autoimmun Rev., 3 (15).

Gauntt, C. J., Arizpe, H. M., Higdon, A. L., Wood, H. J., Bowers, D. F., Rozek, M. M. \& Crawley, R. (1995). Molecular mimicry, anti-coxsackievirus B3 neutralizing monoclonal anticorpos, and myocarditis. J. Immunol., 154 (4), 2983-2995.

Getts, D. R., Chastain, E. M. L. \& Terry, R. L. M. (2013). Infecção por vírus SD, imunidade antiviral e autoimunidade. Immunol. Rev., 255 (7), $197-209$.

Kim, B., Kaistha, S. D. \& Rouse, B. T. (2006). Vírus e autoimunidade. Autoimmunity, 39 (3), 71-77. 
Research, Society and Development, v. 10, n. 11, e432101119945, 2021

(CC BY 4.0) | ISSN 2525-3409 | DOI: htttp://dx.doi.org/10.33448/rsd-v10i11.19945

Lerner, A., Arleevskaya, M., Schmiedl, A. \& Matthias, T. (2017). Microbes and Viruses Are Bugging the Gut in Celiac Disease. Frente. Microbiol., 8 (3), 1392-1399.

Smatti, M. K., Cipriano, F. S., Nasrallah, G. H., Thani, A. A, Almishal, R. O. \& Yassine, H. M. (2019). Vírus e autoimunidade: uma revisão sobre a interação potencial e mecanismos moleculares. Viruses, $11(8), 750-762$.

Theofilopoulos, A., Kono, D. \& Baccala, R. (2017). The multiple pathways to autoimmunity. Nat Immunol., 18 (7), 716-724

Wang, L., Wang, F. S. \& Gershwin, M. E. (2015). Human autoimmune diseases: a comprehensive update. J. Intern. Med. 278 (1), $369-395$

Zinserling, V. A., Vashukova, M. A., Vasilyeva, M. V. \& Isakov, A. N. (2020). Issues of pathology of a new coronavirus infecção COVID-19. Jurnal infectologii, 12 (2): 5-11. 